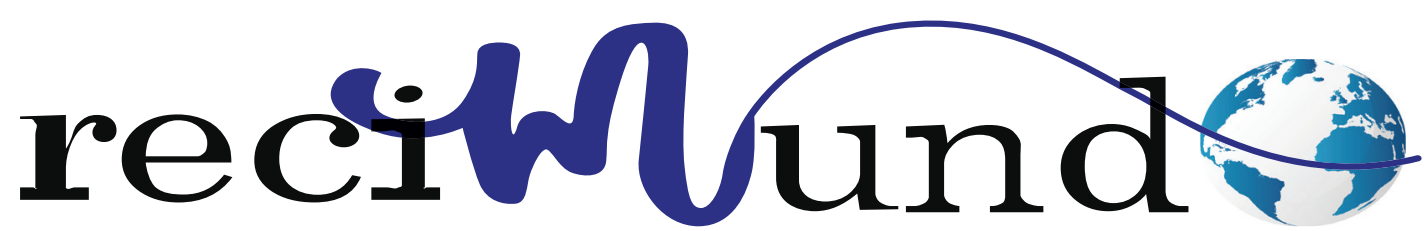

Revista Científica Mundo de la Investigación y el Conocimiento

DOI: 10.26820/recimundo/4.(2).mayo.2020.75-85

URL: http://recimundo.com/index.php/es/article/view/825

EDITORIAL: Saberes del Conocimiento

REVISTA: RECIMUNDO

ISSN: 2588-073X

TIPO DE INVESTIGACIÓN: Artículo de Revisión

CÓDIGO UNESCO: 5910 Opinión Pública;

5910.02 Medios de Comunicación de Masas

PAGINAS: 75-85

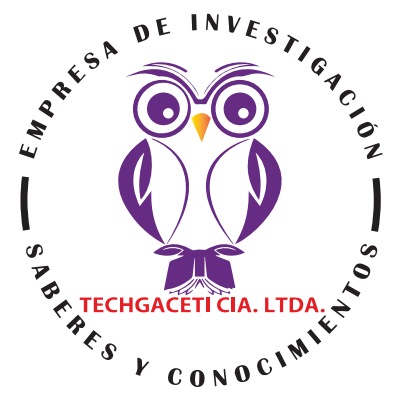

\title{
Estrategias viables de comunicación ante un estado de excepción para una correcta socialización de los colectivos reales
}

Viable communication strategies in a state of exception for the correct socialization of real groups

Estratégias de comunicação viáveis em um estado de exceção para a correta socialização de grupos reais

Gina Arsenia Morán Cárdenas'; Oswaldo Zavala Palacios²; Myriam Rossana Mendoza Solorzano³

RECIBIDO: 15/03/2020 ACEPTADO: 20/03/2020 PUBLICADO: 20/05/2020

1. Magister en Comunicación y Desarrollo; Licenciada en Ciencias de la Educación Especialidad Supervisión y Administración Educativa; Universidad de Guayaquil; Guayaquil, ginapolaris@hotmail.com; (D) https://orcid. org/0000-0002-0423-8644

2. Magister en Diseño Curricular; Diploma Superior en Diseño Curricular por Competencias; Licenciado en Ciencias de la Comunicación Social; Universidad de Guayaquil; Guayaquil, ozavalapalacios@hotmail.com; (D) https://orcid.org/0000-0003-3420-4311

3. Magister en Psicología Laboral con mención en Desarrollo Humano y de la Organización; Ingeniero Comercial; Universidad de Guayaquil; Guayaquil, myriam17feb@hotmail.com; iD https://orcid.org/0000-0002-0469-6581

\author{
CORRESPONDENCIA \\ Gina Arsenia Morán Cárdenas \\ ginapolaris@hotmail.com \\ Guayaquil, Ecuador
}




\section{RESUMEN}

La comunicación se define como un conjunto de elementos en interacción en donde toda modificación de uno de ellos afecta las relaciones entre los otros elementos. Se sustenta a partir de la existencia de dos elementos: la energía que lo mueve y la circulación de informaciones. El proceso de la comunicación involucra varios elementos, que son necesarios tanto para emitir un mensaje como para decodificarlo y comprenderlo a fin de ofrecer una respuesta o acción: emisor, receptor, canal, canal de comunicación, contexto, ruido y retroalimentación. Los tipos de comunicación abordados: comunicación verbal y escrita, intrapersonal, individual, intergrupal, intragrupal y colectiva. La Comunicación en situaciones de crisis es un proceso interactivo de intercambio de información y opinión entre personas, grupos e instituciones; suele incluir múltiples mensajes acerca de la naturaleza del riesgo o expresar preocupaciones, opiniones o reacciones acerca de los mensajes sobre el riesgo o de los arreglos legales e institucionales para la gestión del riesgo. Las violentas protestas ocurridas en Ecuador durante octubre de 2019 por el alza del precio de los combustibles que llevaron a la declaración del estado de excepción constituyen evidencia de cómo establecer una estrategia comunicacional coherente. El proceso de socialización se define como uno continuo que está en permanente desarrollo. La autorregulación es el fundamento de la socialización, requiere conciencia cognoscitiva y de forma importante, control emocional. El proceso de influencia socializadora de la relación padres-hijos, se han considerado como los principales agentes de socialización: la familia, la escuela, el grupo de iguales, los medios de comunicación y las nuevas tecnologías. Se aplicó una metodología descriptiva, con un enfoque documental, es decir, revisar fuentes disponibles en la red, con contenido oportuno y relevante para dar respuesta a lo tratado en el presente artículo.

Palabras clave: Estrategias comunicacionales, agentes socializadores, tecnología, estado de excepción, socialización, crisis, gobernabilidad.

\section{ABSTRACT}

Communication is defined as a set of interacting elements where any modification of one of them affects the relationships between the other elements. It is sustained by the existence of two elements: the energy that moves it and the circulation of information. The communication process involves several elements, which are necessary both to emit a message and to decode and understand it in order to offer a response or action: sender, receiver, channel, communication channel, context, noise and feedback. The types of communication addressed: verbal and written communication, intrapersonal, individual, intergroup, intragroup and collective. Communication in crisis situations is an interactive process of exchange of information and opinion between people, groups and institutions; it usually includes multiple messages about the nature of the risk or expresses concerns, opinions or reactions about the risk messages or legal and institutional arrangements for risk management. The violent protests that occurred in Ecuador during October 2019 due to the rise in the price of fuels that led to the declaration of the state of emergency constitute evidence of how to establish a coherent communication strategy. The socialization process is defined as a continuous one that is in permanent development. Self-regulation is the foundation of socialization, it requires cognitive awareness and, importantly, emotional control. The process of socializing influence of the parent-child relationship has been considered as the main agents of socialization: the family, the school, the peer group, the media and new technologies. A descriptive methodology was applied, with a documentary approach, that is, reviewing sources available on the network, with timely and relevant content to respond to what is discussed in this article.

Keywords: Communication strategies, socializing agents, technology, state of exception, socialization, crisis, governance.

\section{RESUMO}

A comunicação é definida como um conjunto de elementos em interação, onde qualquer modificação de um deles afeta os relacionamentos entre os outros elementos. É sustentado pela existência de dois elementos: a energia que a move e a circulação de informações. O processo de comunicação envolve vários elementos, necessários para emitir uma mensagem e decodificá-la e compreendê-la para oferecer uma resposta ou ação: remetente, receptor, canal, canal de comunicação, contexto, ruído e feedback. Os tipos de comunicação abordados: comunicação verbal e escrita, intrapessoal, individual, intergrupo, intragrupo e coletivo. A comunicação em situações de crise é um processo interativo de troca de informações e opiniões entre pessoas, grupos e instituições; geralmente inclui várias mensagens sobre a natureza do risco ou expressa preocupações, opiniões ou reações sobre as mensagens de risco ou arranjos legais e institucionais para o gerenciamento de riscos. Os violentos protestos que ocorreram no Equador em outubro de 2019 devido ao aumento do preço dos combustíveis que levaram à declaração do estado de emergência constituem evidências de como estabelecer uma estratégia de comunicação coerente. O processo de socialização é definido como contínuo e em desenvolvimento permanente. A auto-regulação é a base da socialização, requer consciência cognitiva e, principalmente, controle emocional. O processo de influência socializante da relação pai-filho tem sido considerado como os principais agentes da socialização: a família, a escola, o grupo de pares, a mídia e as novas tecnologias. Foi aplicada uma metodologia descritiva, com abordagem documental, ou seja, revisando as fontes disponíveis na rede, com conteúdo oportuno e relevante para responder ao que é discutido neste artigo.

Palavras-chave: Estratégias de comunicação, agentes socializadores, tecnologia, estado de exceção, socialização, crise, governança. 


\section{ESTRATEGIAS VIABLES DE COMUNICACIÓN ANTE UN ESTADO DE EXCEPCIÓN PARA UNA CORRECTA SOCIALIZACIÓN DE LOS COLECTIVOS REALES}

\section{Introducción}

Los hechos violentos y protestas ocurridos en Ecuador durante octubre de 2019 es una gran crisis, visto como sucesos que pueden llegar a cambiar la percepción sobre los gobiernos y los presidentes y sociedad en general. En ella se aprecia: el factor sorpresa, la desestabilización, el estrés y la reducción de los tiempos que condiciona la toma de decisiones, la emoción de los pú-

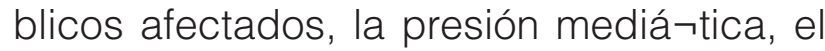
desafío para la imagen de las autoridades y el peligro para la posición de poder de los gobernantes.

El impacto de lo ocurrido, obligó a las personas a modificar abruptamente los hábitos y rutinas, la restricción a la libre circulación cambió la forma de trabajar, socializar y consumo durante el tiempo de disturbios. La tecnología fue una herramienta que colaboró durante el toque de queda para la sociedad ecuatoriana, especialmente en las provincias, facilitando a la población estar informado, trabajar, entretenerse y relacionarse en forma segura con otros grupos de interés, especialmente durante un estado de excepción.

La sociedad ecuatoriana estaba sumamente fragmentada, mostrando muchas debilidades que pasaron desapercibidas, requiere un tipo de comuni-cación muy autónoma. Durante los días de paralización de transportistas y posteriores focos de violencia, el Gobierno, indígenas y estratos sociales perdieron la capacidad de ejercer la protesta social en un ámbito de paz, necesitando una comunicación orientada a la gestión de las situaciones de emergencia, y poco relacionada con los otros tipos de comunicación política, como la comunicación gubernamental o institucional (Garrido, 2020).

Muchos de estos cambios llegaron para quedarse presente en las sociedades en tiempos post protestas en Ecuador, algunas como las implicaciones y sostenibilidad de los subsidios, especialmente los relativos al transporte. La tecnología aliviará las condiciones de socialización de las personas haciéndolo más extensivo el mensaje a las masas pero también requerirá mayor planificación del contenido y vocero. Existen estrategias que permiten comunicar y comunicarse en forma efectiva ante estados de excepción abordadas en el presente artículo.

\section{Metodología}

Esta investigación está dirigida al estudio del tema "Estrategias viables de comunicación ante un estado de excepción para una correcta socialización de los colectivos reales". Para realizarlo se usó una metodología descriptiva, con un enfoque documental, es decir, revisar fuentes disponibles en la red, cuyo contenido sea actual, publicados en revistas de ciencia, disponibles en Google Académico, lo más ajustadas al propósito del escrito, con contenido oportuno y relevante desde el punto de vista científico para dar respuesta a lo tratado en el presente artículo y que sirvan de inspiración para realizar otros proyectos. Las mismas pueden ser estudiadas al final, en la bibliografía.

\section{Resultados}

La comunicación según Paul Watzlawick se define como un "conjunto de elementos en interacción en donde toda modificación de uno de ellos afecta las relaciones entre los otros elementos" (Rizo, 2011). Esta definición se aproxima al concepto de sistema, cuyo funcionamiento se sustenta a partir de la existencia de dos elementos: la energía que lo mueve, los intercambios, las fuerzas, los móviles, las tensiones y por el otro, la circulación de informaciones y significaciones, misma que permite el desarrollo, la regulación y el equilibro del sistema.

La comunicación es un sistema abierto de interacciones, inscritas siempre en un con-

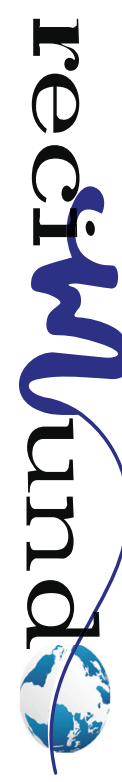


texto determinado que obedece a ciertos principios (Rizo, 2011):

- Principio de totalidad: plantea que un sistema no es una simple suma de elementos sino que posee características propias, diferentes de los elementos que lo componen tomados por separado.

- Principio de causalidad circular: establece que el comportamiento de cada una de las partes del sistema forman parte de un complicado juego de implicaciones mutuas, de acciones y reacciones.

- Principio de regulación: afirma que no puede existir comunicación que no obedezca a un número mínimo de reglas, normas, convenciones. Estas reglas son las que, precisamente, permiten el equilibrio del sistema.

Los tres principios constituyen una de las principales aportaciones de la Escuela Californiana de Palo Alto a la comprensión de la comunicación. En la obra clásica de Watzlawick, Beavin y Jackson, Teoría de la comunicación humana (1971), se hace énfasis en estos principios básicos del sistema. El principio de causalidad circular se explica a partir del concepto de retroalimentación, proveniente del enfoque de Norbert Wiener en 1983. El principio de regulación es nombrado a partir del término equifinalidad, comprendido como el conjunto de elementos que dotan de estabilidad al sistema. Todo lo anterior respalda que la comunicación, ante todo, es un sistema abierto de interacciones.

Las primeras definiciones de comunicación apuntan a su vertiente interpersonal, relacional, más que a la concepción mediada que ha prevalecido y dominado el pensamiento sobre comunicación a lo largo de su historia como al campo académico. El predominio de los medios de difusión oscurece las aportaciones de todo lo concerniente al diálogo, al vínculo entre seres humanos, a la capacidad de éstos para comunicarse consigo mismos, con los otros y con el en- torno físico y simbólico en el que se desenvuelven en la actualidad.

\section{Elementos de la comunicación}

El proceso de la comunicación involucra varios elementos, que son necesarios tanto para emitir un mensaje como para decodificarlo y comprenderlo a fin de ofrecer una respuesta o acción. La comunicación se ha desarrollado de manera correcta cuando el receptor interpreta el mensaje y ofrece una respuesta al emisor, y así sucesivamente. La siguiente tabla los resume:

Tabla 1. Elementos de la comunicación

\begin{tabular}{|c|c|}
\hline $\begin{array}{l}\text { Emisor: es la persona } \\
\text { que tiene la iniciativa } \\
\text { de compartir una infor- } \\
\text { mación e inicia la comu- } \\
\text { nicación emitiendo un } \\
\text { mensaje. }\end{array}$ & $\begin{array}{l}\text { Receptor: es la per- } \\
\text { sona que recibe e in- } \\
\text { terpreta un mensaje, } \\
\text { previamente enviado } \\
\text { por un emisor. El recep- } \\
\text { tor puede responder y } \\
\text { ocupar el lugar del emi- } \\
\text { sor, generando una ac- } \\
\text { ción comunicativa. }\end{array}$ \\
\hline $\begin{array}{l}\text { Código: son los signos } \\
\text { empleados para transmi- } \\
\text { tir un mensaje. El código } \\
\text { puede ser verbal o no } \\
\text { verbal. }\end{array}$ & $\begin{array}{l}\text { Mensaje: se refiere } \\
\text { al contenido que se } \\
\text { transmite y que puede } \\
\text { ser una información, } \\
\text { opinión, sentimiento o } \\
\text { idea. }\end{array}$ \\
\hline $\begin{array}{l}\text { Canal de comunica- } \\
\text { ción: medio a través del } \\
\text { cual se envía el mensaje } \\
\text { entre el emisor y el re- } \\
\text { ceptor. Por ejemplo, el } \\
\text { aire, el teléfono móvil, } \\
\text { el teléfono fijo, el correo } \\
\text { electrónico, entre otros. }\end{array}$ & $\begin{array}{l}\text { Contexto: espacio o } \\
\text { situación en la cual se } \\
\text { desarrolla la comuni- } \\
\text { cación. Se toman en } \\
\text { cuenta las circunstan- } \\
\text { cias concretas en las } \\
\text { se desarrolla el acto } \\
\text { comunicativo. }\end{array}$ \\
\hline $\begin{array}{l}\text { Ruido: pueden aparecer } \\
\text { ruidos o alteraciones fí- } \\
\text { sica externas al acto co- } \\
\text { municativo que afectan o } \\
\text { distorsionan el mensaje } \\
\text { que se envía. }\end{array}$ & $\begin{array}{l}\text { Retroalime ntación: } \\
\text { feedback al envío y re- } \\
\text { cepción de mensajes } \\
\text { de manera constante } \\
\text { entre los interlocutores. }\end{array}$ \\
\hline
\end{tabular}

Fuente: (Morales, 2019) 


\section{ESTRATEGIAS VIABLES DE COMUNICACIÓN ANTE UN ESTADO DE EXCEPCIÓN PARA UNA CORRECTA SOCIALIZACIÓN DE LOS COLECTIVOS REALES}

\section{Tipos de comunicación}

Comunicación verbal: consiste en la utilización de las palabras para comunicarse con otros miembros y emitir un mensaje. Existen diferentes tipos de comunicación verbal: la comunicación oral (llanto, silbidos, sonrisa y palabras) y escrita (es un tipo de lenguaje corporal con el que se transmite un mensaje a otras personas a través de los movimientos o gestos: expresión facial, la mirada, la postura y la actitud).

- Intrapersonal: el emisor y el receptor es la misma persona.

- Individual: es aquella en que se produce de un sujeto a otro sujeto, o de un emisor a un receptor.

- Intergrupal: se genera cuando interactúan dos o más grupos. Ejemplo entre un grupo de profesores y un grupo de alumnos (Mañez, 2018).

- Intragrupal: es cuando se comunican dos o varias personas pero a diferencia con el anterior éstas pertenecen al mismo grupo.

- Colectiva: se produce cuando dos o más personas intercambian mensajes.

También existen diferentes tipos de canales de comunicación en función de la tecnología. Las principales formas son (Mañez, 2018):

- Comunicación telefónica: a través de telefonía fija y móvil. En el caso de telefonía celular existen varias aplicaciones muy oportunas en tiempos de confinamiento que se explicaran en otro apartado.

- Comunicación por las redes sociales: han cambiado la forma de comunicarnos e interactuar con otras personas y se han convertido en uno de los canales de comunicación más utilizados por las personas para relacionarse con sus amistades.

- Comunicación por email: especialmente usado para asignaciones educativas y negocios.
- Televisión: es un tipo de comunicación de masas que permite enviar un mensaje a un número muy amplio de personas.

- Radio: facilita hacer llegar un mensaje a un número amplio de receptores.

\section{Comunicación en tiempo de Estado de excepción}

El presidente Ecuatoriano Lenin Moreno decretó el 3 de octubre del 2019 el estado de excepción en Ecuador con el propósito de precautelar la seguridad ciudadana ante las protestas que ocurren después del anuncio de medidas económicas. El Presidente Moreno establece: "Las medidas que tomamos en conjunto están en firme, no existe posibilidad de cambiar, principalmente las relacionadas con el subsidio que causa tanto daño al país que distorsionaba la economía" (España, 2019).

Este estado de excepción figura establecida en el Art. 164 de la Constitución del país, implica que se restringen algunas libertades y se permite a las autoridades tomar bienes públicos o privados para restablecer la normalidad de las actividades sociales, además de dotar de custodia adicional a las áreas estratégicas como refinerías, aeropuertos y plantas de generación.

\section{Aspectos establecidos en este decreto}

Se trata de un documento de 10 artículos en el que se establece lo siguiente (Muñoz, 2010):

1. Se declara el estado de excepción con el objetivo de recuperar el orden público.

2. Se moviliza a las Fuerzas Armadas y la Policía Nacional.

3. Se suspende el ejercicio del derecho a la libertad de asociación y reunión.

4. Se limita la libertad de tránsito en todo el país, excepto del transporte público.

5. Se permiten las requisiciones que sean necesarias por extrema necesidad.

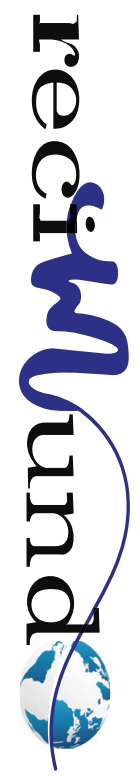


6. Se establece como zona de seguridad todo el territorio nacional.

7. Se autoriza la utilización de los fondos públicos que sean necesarios del Ministerio de Economía y Finanzas.

8. Se extiende durante 60 días.

9. Se notifica la declaratoria a la Asamblea Nacional, a la Corte Constitucional y a los organismos internacionales.

10. Se acuerda que la aplicación del Decreto Ejecutivo recae en los ministros de Gobierno, Defensa Nacional y Economía y Finanzas.

El decreto de estado de excepción según la Constitución de Ecuador, tendrá vigencia por un plazo máximo de sesenta días. Si las causas que lo motivaron persisten podrá renovarse hasta por treinta días más, lo cual deberá notificarse. Si el Presidente no renueva el decreto de estado de excepción o no lo notifica, éste se entenderá caducado. En una circunstancia tan delicada como esta, es importante tener cuidado con lo que se dice en materia de comunicación.

Las estrategias de comunicación son un componente integral de los planes nacionales contra un estado de excepción, permitiendo que las ideas se conviertan en acciones. Considerando la posible repercusión de una situación volátil, un grupo de expertos en materia comunicacional propone: "realizar planes detallados sobre qué se debe comunicar, cómo hacerlo, quién debe hacerlo y a quién se debe informar $y$, se han de revisar en repetidas ocasiones para todas las fases del estado de excepción y todo tipo de público" (H. Urbina, 2016).

La comunicación con el público, con usuarios directos dentro del sistema, universidades y otros actores en general, es fundamental durante una emergencia para el control de cualquier crisis. Tienen un rol especial las estrategias de comunicación diseñadas con antelación para tratar las posibles situaciones, objetivos detallados, públicos destinatarios, mensajes clave, he- rramientas o canales y planes de acción. Los objetivos de la comunicación antes un hecho violento son educar, informar, recomendar, preparar y prevenir.

La Comunicación en situaciones de crisis es un proceso interactivo de intercambio de información y opinión entre personas, grupos e instituciones; suele incluir múltiples mensajes acerca de la naturaleza del riesgo o expresar preocupaciones, opiniones o reacciones acerca de los mensajes sobre el riesgo o de los arreglos legales e institucionales para la gestión del riesgo.

Los medios de comunicación son espacios clave que contribuyen a reducir la cantidad de rumores y evitar el pánico, sin embargo, si no están bajo una coordinación constante por la autoridad respectiva (local, regional y nacional), pueden causar retrasos en el control de la crisis y minar la confianza de la gente.

Se propone:

Un pilar para mantener informada a las comunidades entre medios de comunicación, gobierno y organismos mundiales, se debe incluir al ciudadano digital, por lo que las redes (facebook, twitter, instagram entre otros) sirven para difundir la información y como plataforma para discusión. (H. Urbina, 2016)

Se debe utilizar un lenguaje apropiado, que no implique sensacionalismo alguno, ni emitir mensajes alarmistas, xenófobos y racistas, como advierte la Asociación Española de Comunicación Científica (AECC). Aprovechar el entorno digital para circular información útil y fidedigna, en diversos formatos (videos o infografías por whatsapp), diversos soportes (apps, sitios, antenas, folletines) y desarrollar un periodismo transmedia, de manera de compartir distintas narrativas en audio, video y texto, que beneficien a la audiencia y eduquen a la opinión 


\section{ESTRATEGIAS VIABLES DE COMUNICACIÓN ANTE UN ESTADO DE EXCEPCIÓN PARA UNA CORRECTA SOCIALIZACIÓN DE LOS COLECTIVOS REALES}

pública frente a la crisis (Rodríguez, 2020).

El proceso de comunicación en estos casos ha evolucionado aceleradamente, los usuarios (más activos gracias a las nuevas tecnologías), recogen información, la comentan y generan corrientes de opinión, pero si estas personas difunden información errónea, pueden agravar la situación de un país o región entera. Ingresar en ese modelo de comunicación es un desafío a superar por las autoridades. Cuando esto sucede la comunicación de crisis pretende ayudar a las personas a sobrellevar sus sentimientos y a enfrentarse al peligro de forma eficaz, considerando (Organización Panamericana de la Salud, 2016):

- Confianza: uno de los objetivos es establecer una relación de confianza del público con aquellos que manejan la situación de emergencia.

- Anuncio temprano: el primer anuncio oficial debería llegar en tiempo real, con la mayor simplicidad y alcance posibles. Por el contrario, otras versiones alternativas aparecerán. Las informaciones deben ser actualizadas en la medida que hubiera nuevas noticias o resultados.

- Transparencia: información clara, de fácil comprensión, completa y basada en los hechos contribuye a ganar la confianza del público. Ser transparente ayuda a que el público comprenda el proceso de búsqueda de información, evaluación y de toma de decisión durante una emergencia.

- Planificación: las actividades de comunicación tienden a ser elaboradas de una manera rápida e intuitiva sobreponiéndose a la necesidad de planificar. Tanto antes, como durante y después de una emergencia, una planificación previa capacita a responder más rápido y eficazmente a un desafío inmediato.

- Tomar en consideración al público: las convicciones y creencias del público deben ser consideradas y aunque sean erróneas no deben ser ignoradas y mu- cho menos ridiculizarlas.

\section{Estrategia de comunicación}

La estrategia de comunicación es una serie de elecciones que permiten ubicar los momentos y los espacios más convenientes, para alcanzar un estilo comunicativo, un sello personal de la organización, que deberán respetar en la ejecución de todos los procesos tanto laborales como humanos. Berracoli (1998) señala que una estrategia de comunicación se basa en "una serie de principios estratégicos que ayudan a mejorar el servicio interno y externo que brinda la organización u ente a su personal, a sus proveedores y a su público consumidor" (Arellano, 2008). Se pone interés en la selección de los discursos integradores y homogéneos, para que los ciudadanos realicen sus actividades con la misma lógica de calidad, innovación, respeto, participación, desarrollo, productividad y lo más importante, sin violencia.

Una estrategia de comunicación, fomenta cuantitativa como cualitativamente intercambios de información, con el objetivo de que la comunidad conozca lo que sucede en su entorno, así como, servir para estimular una actitud positiva sobre las condiciones socioculturales en que se encuentra el país, para determinar la viabilidad de promover, modificaciones de los valores, las creencias, los ritos y los mitos, hacia las personas dentro su actividad cotidiana y sobre su pertenencia a la comunidad. La estrategia se compone de un proceso técnico el cual opera bajo una lógica de producción, circulación y consumo de información (Manrique, 2016).

Los referentes son elegidos a partir de las necesidades comunicativas de la organización o emisor, sobre el tipo de representaciones sociales y universos simbólicos que desea establecer (Arellano, 2008). La estrategia debe diseñar un procedimiento de retroalimentación, que facilite, comprenda y opere, los cambios que va teniendo la so-

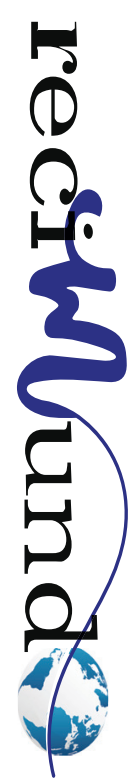


ciedad, brindar de forma eficiente, la información operativa que necesita toda comunidad para realizar sus actividades básicas cotidianas; también para generar interacciones que proyecte y provoque, relaciones reflexivas, que posibiliten construir una sociedad sustentada en acciones exitosas.

Define contenidos, y propone la cobertura provincial, así como los lugares de intervención a nivel departamental y local; en tal sentido incluye, entre otros que se propongan los siguientes aspectos (Organización Panamericana de la Salud, 2016):

- Comunicación ante un hecho violento, concebida desde lo que se ha llamado comunicación de riesgo para compartir información rápidamente y crear confianza.

- Promoción dirigida a los responsables de tomar decisiones y formular políticas, con el propósito de recaudar fondos, aunar esfuerzos y obtener compromisos políticos y sociales.

- Relaciones proactivas con los medios para promover el flujo responsable, exacto y útil de información a través de los medios nacionales, regionales y locales.

- Movilización social para garantizar una mayor participación de la comunidad mediante la creación de coaliciones y alianzas.

- Comunicación para lograr cambios de comportamiento, actitudes y prácticas entre grupos específicos a través de la investigación, el seguimiento, la evaluación, la capacitación, la comunicación interpersonal, la publicidad social y la propaganda educativa.

\section{Evaluación de las estrategias de comuni- cación}

A partir de estos planteamientos básicos es necesario proponer una evaluación de la estrategia de comunicación, generando planes de contingencia en caso de requerir una reorientación de los mensajes, se generen nuevos grupos objetivo, o planes de acción en comunicación no previstos en la estrategia inicial. Teniendo en cuenta estos aspectos se espera llegar a generar las actitudes, comportamientos y prácticas necesarias para la prevención y mitigación de revueltas violentas y protestas. Lo que se requiere (Garrido, 2020):

- Conformar un equipo de crisis.

- Formular una estrategia clara y concisa.

- Establecer metas: prevenir que exista desconfianza.

- Establecer equipo de crisis: Jefe, técnicos, voceros.

- Identificar personas que deben estar informadas (protocolos de comunicación).

- Preparar y capacitar voceros (nacionales, locales) y tener la lista.

- Asegurar que TODOS los actores conozcan a los voceros.

- Establecer estrategias de comunicación.

- Definir mensajes, asegurar la capacitación, definir y asignar tareas.

Una mirada a la socialización como proceso El proceso de socialización puede definirse como continuo que está en permanente desarrollo. Se inicia desde el momento del nacimiento, va progresando y evolucionando durante todas las etapas del ciclo vital. La socialización exige, por tanto, adoptar unos patrones sociales determinados como propios, con el objetivo de conseguir la necesaria autorregulación que permita una cierta independencia a la hora de adaptarse a las expectativas de la sociedad. La autorregulación es el fundamento de la socialización, requiere conciencia cognoscitiva y de forma importante, control emocional.

Por otra parte, Papalia, Olds y Feldman (2001) afirman: "Lo que ocurre en el mundo del niño es significativo, pero no es la totalidad de la historia. Cada uno sigue escribiendo su propia historia de desarrollo humano mientras vive" (Yubero, 2015). Los 


\section{ESTRATEGIAS VIABLES DE COMUNICACIÓN ANTE UN ESTADO DE EXCEPCIÓN PARA UNA CORRECTA SOCIALIZACIÓN DE LOS COLECTIVOS REALES}

agentes de socialización (aquellas personas o instituciones que hacen posible la efectividad de la interiorización de la estructura y procesos sociales) se van diversificando a medida que se incrementan los contextos sociales de acción del individuo, pasándose de la exclusividad de la familia a la influencia de otros agentes externos a la misma.

Después de la familia del niño, éste empieza a interesarse por personas diferentes a las de su hogar, especialmente el grupo de iguales, el cual alcanzará su pico en el período de la adolescencia. Ello supone la conversión del niño en arquitecto de su mundo social, desarrollando las características más salientes del mundo adulto en que crecen, pueden ir adquiriendo un gran bagaje de conocimiento social, les permiten progresar en su integración.

Mediante el proceso de socialización, el individuo se afilia al grupo, desarrolla una identidad y con ello, se asocia en un número determinado de categorías sociales. La interacción social es el aspecto central de la socialización, puede considerarse como un proceso de relaciones a través del cual se desarrollan determinadas formas de pensar, sentir y actuar que son características de un grupo. Este proceso no sólo producirá cambios en el propio individuo, sino en el sistema de relaciones que establezca, modificando y adaptándose sus propias normas de relación.

La socialización es un proceso de modelado cultural: somos socializados a través del aprendizaje de las prácticas culturales que realizan los miembros del grupo escogido y que enseñan tanto los modos de actuar y de expresar emociones, como las formas de reaccionar ante determinadas situaciones, así como el establecimiento de esquemas relacionales.

Los agentes de socialización son las personas e instituciones que se ocupan de que la interiorización de la estructura social se haga efectiva (Yubero, 2015). Cada una de las personas con las que interaccionamos a lo largo de la vida es un agente socializador, siempre y cuando posea la capacidad de influir en nuestro comportamiento, en la dirección que él mismo marca y que coincide con la orientación aceptada socialmente. Dentro de este proceso de interacción, los agentes poseen distintas posibilidades de influencia, acotadas en el tiempo y en función de las estructuras de relación establecidas, utilizan una amplia gama de reforzadores con la intención modificar y adaptar la conducta en la dirección preestablecida socialmente.

Torregrosa y Fernández Villanueva (1984), consideran que:

También las personas socializadas mantienen sobre los agentes de socialización un poder potencial, que difícilmente podría traducirse a un determinado porcentaje del total de la influencia que se pone en juego en la relación socializadora, pero mantiene un margen de indeterminación sobre el producto final de esa relación. (Yubero, 2015)

El proceso de disminución de la influencia socializadora de la relación padres-hijos, se han considerado como los principales agentes de socialización: la familia, la escuela, el grupo de iguales, los medios de comunicación - la televisión - y, actualmente, tendríamos que añadir la influencia de las nuevas tecnologías como es el caso de Internet, tomando fuerza en tiempos de toque de queda.

Durante los hechos acontecidos en Octubre de 2019 en Ecuador, los servicios de transporte público empezaron paulatinamente a operar en varias ciudades, mientras que el gobierno anunciaba que estaría autorizando un incremento en las tarifas de transpor-

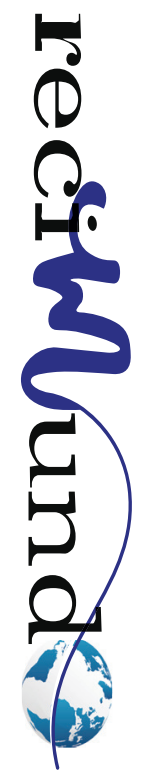


te urbano de entre 5 y 10 centavos de dólar. Sin embargo esa normalidad no llegó en forma rápida a las provincias. Se han presentado disturbios en varias zonas del país, particularmente de parte de la población indígena que siguió en pie de protesta.

Estas comunidades continuaron con las manifestaciones, lanzando consignas en su idioma ancestral contra lo que denominan el "paquetazo" (serie de medidas de austeridad anunciadas por el presidente Moreno). Han obstaculizado carreteras con piedras, palos y neumáticos en varios sitios e inclusive hubo un enfrentamiento con militares que intentaban despejar una de las vías bloqueadas en la provincia andina de Cotopaxi, según informó la agencia EFE (Images, 2019).

La CONAIE, la mayor central indígena del país, se sentó y logro algunos de sus propósitos de lucha, gracias a la comunicación establecida con representantes del gobierno del presidente Moreno, sirviendo de ejemplo de estrategia comunicacional con grupos de impacto en la socialización del pueblo indígena.

\section{Conclusiones}

La comunicación es un proceso que permite intercambiar información y establecer un tipo de relación social con quienes nos rodean. Se trata de un acto dinámico y sistemático que logra que las personas se comuniquen y establezcan opiniones o posturas según sea el caso. En este proceso participan dos o más personas, (un emisor y un receptor) capaces de enviar, decodificar e interpretar los códigos intercambiados entre ambos.

El acto comunicativo es un proceso a través del cual las personas comparten información, opiniones, sentimientos, experiencias y conocimiento. En la actualidad se han desarrollado diversos canales de comunicación gracias a los avances tecnológicos y científicos que, incluso, ayudan a quienes tienen algún tipo de discapacidad visual, auditiva $u$ oral, para que puedan comunicarse con los demás. La importancia de la comunicación radica en establecer relaciones humanas que permitan a las personas cumplir con el objetivo de transmitir una información o sentimientos, lograr un entendimiento, generar una acción, entre otros.

Una estrategia de comunicación, fomenta cuantitativa como cualitativamente intercambios de información, con el propósito de que la comunidad conozca lo que sucede en su entorno, estimular una actitud positiva sobre las condiciones socioculturales en que se encuentra la sociedad, determinar la viabilidad de promover modificaciones de los valores, las creencias, los ritos y los mitos, hacia las personas dentro su actividad cotidiana y sobre su pertenencia a la comunidad. La estrategia se compone de un proceso técnico el cual opera bajo una lógica de producción, circulación y consumo de información.

El proceso de socialización puede definirse como continuo, que está en permanente desarrollo. Se inicia desde el momento del nacimiento, va progresando y evolucionando durante todas las etapas del ciclo vital. La socialización exige, por tanto, adoptar unos patrones sociales determinados como propios, con el objetivo de conseguir la necesaria autorregulación que permita una cierta independencia a la hora de adaptarse a las expectativas de la sociedad. La autorregulación es el fundamento de la socialización, requiere conciencia cognoscitiva y de forma importante, control emocional.

También son importantes todas las maneras de comunicar y dar respuestas creativas que pueden hacer todos los medios, especialmente el gobierno ante un estado de excepción. Usando un lenguaje conciliador, planificando el mensaje y la información compartida más próximos a su audiencia, conocedores de su territorio y de quiénes 


\section{ESTRATEGIAS VIABLES DE COMUNICACIÓN ANTE UN ESTADO DE EXCEPCIÓN PARA UNA CORRECTA SOCIALIZACIÓN DE LOS COLECTIVOS REALES}

los escuchan y necesitan a fin de minimizar un hecho violento como el ocurrido en Ecuador en octubre de 2019.

Considerar la labor, gestión y auxilio que prestan instituciones y organizaciones sociales y locales, como una fuente válida y necesaria frente a las fuentes nacionales $u$ oficiales demandadas por la contingencia y multiplicadas por muchos medios, incluso los tecnológicos permiten comunicaciones más asertivas, generando mayor confianza tanto en el mensaje como en el interlocutor permiten generar menos ruido, rumores y por ende angustia en el colectivo.

\section{Bibliografía}

Arellano, E. (2008). La Estrategia de Comunicación Orientada al Desarrollo de la Cultura Organizacional. Razón y Palabra, 13(2). Obtenido de https:// www.redalyc.org

España, S. (03 de Octubre de 2019). Presidente Lenín Moreno decreta estado de excepción y ratifica las medidas económicas. Obtenido de El Comercio: https://www.elcomercio.com

Garrido, I. C. (2020). La pandemia del Coronavirus: Estrategias de Comunicación en Crisis. Más Poder Local(41), 12 - 19. Obtenido de https://dialnet. unirioja.es

H. Urbina, D. N. (2016). Comunicación efectiva y ética en casos de epidemias y pandemias. Archivos Venezolanos de Puericultura y Pediatría, 79(4). Obtenido de http://ve.scielo.org

Images, G. (06 de Octubre de 2019). Estado de excepción en Ecuador: las comunidades indígenas se mantienen movilizadas contra las medidas del gobierno. Obtenido de BBC Mundo: https://www. bbc.com
M. Tilman, A. W. (22 de Mayo de 2020). ¿Qué es Zoom y cómo funciona? Más consejos y trucos. Obtenido de Pocket-lint: https://www.pocket-lint. com

Mañez, R. (04 de Marzo de 2018). Los 35 tipos de comunicación y sus características. Obtenido de Marketing and Web: https://www.marketingandweb.es

Manrique, N. (2016). Una Alucinación Consensual. Redes sociales, cultura y socialización. Lima: Fondo Editorial de la Pontificia Universidad Católica de Perú. Obtenido de http://repositorio.pucp.edu. pe

Morales, A. (23 de Agosto de 2019). Qué es la comunicación. Obtenido de Toda Materia: https://www. todamateria.com

Muñoz, L. (04 de Octubre de 2010). Las claves del estado de excepción en Ecuador. Obtenido de France 24: https://www.france24.com

Organización Panamericana de la Salud. (03 de Julio de 2016). Plan de Comunicación ante la Pandemia. Obtenido de Ministerio de Salud y Acción Social: https://www.paho.org

Rizo, M. (2011). Reseña de "Teoría de la comunicación humana" de Paul Watzlawick. Razón y Palabra, 1(75). Obtenido de https://www.redalyc.org

Rodríguez, R. (2020). Coronavirus: cuando la comunicación tradicional y las redes sociales también hacen crisis. Universidad de Chile. Obtenido de https://www.uchile.cl

Yubero, S. (2015). SOCIALIZACIÓN Y APRENDIZAJE SOCIAL. En S. Yubero, Psicología Social, Cultura y Educación (págs. 2 - 24). Obtenido de https:// www.ehu.eus

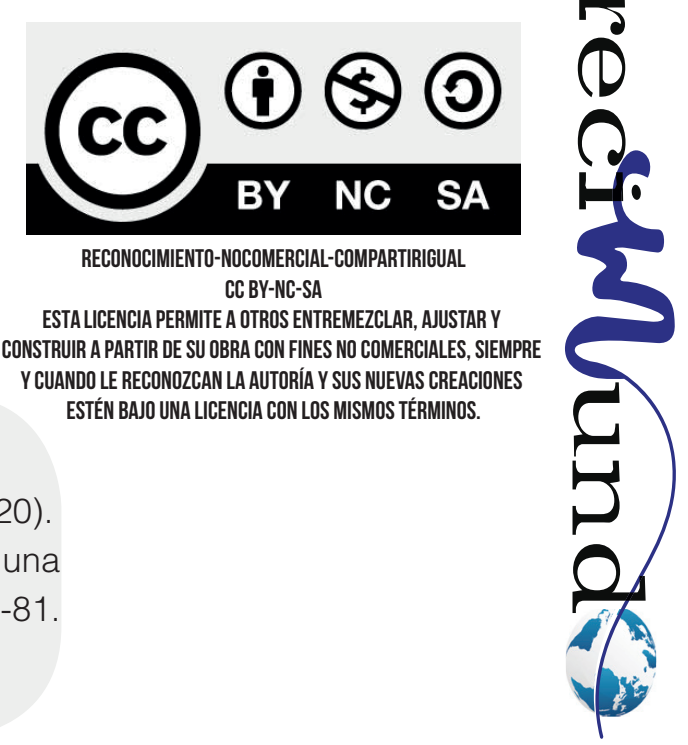

\section{CITAR ESTE ARTICULO:}

Morán Cárdenas, G., Zavala Palacios, O., \& Mendoza Solorzano, M. (2020)

Estrategias viables de comunicación ante un estado de excepción para una correcta socialización de los colectivos reales. RECIMUNDO, 4(2), 71-81. doi:10.26820/recimundo/4.(2).mayo.2020.75-85 